\title{
Decomposition and mineralization of aquatic humic substances (AHS) in treating landfill leachate using the Anammox process
}

\author{
Zhu Liang, Jun-Xin Liu *, Jing Li \\ State Key Laboratory of Environmental Aquatic Chemistry, Research Center for Eco-Environmental Science, Chinese Academy of Sciences, Beijing 100085, PR China
}

\section{A R T I C L E I N F O}

\section{Article history:}

Received 6 June 2008

Received in revised form 23 November 2008 Accepted 24 November 2008

Available online 7 January 2009

\section{Keywords:}

Landfill leachate

Humic substances

Decomposition and mineralization

Anammox process

\begin{abstract}
A B S T R A C T
Aquatic humic substance (AHS) in landfill leachate is resistant to biodegradation, especially in anaerobic habitats. However, we reported here for the first time that AHS was completely biodegraded with the anaerobic ammonium oxidation (Anammox) process. As a result of aromatic-ring cleavage and mineralization, carboxylic and aliphatic organics were significantly produced, the contents of chromophores such as quinoid and ketone were remarkably decreased to decolorize the leachate, and produced carbon dioxide along with increasing carbonate was clearly presented. Of the degraded AHS of $137 \mathrm{mg} \mathrm{L}^{-1}, 51 \mathrm{mg} \mathrm{L}^{-1}$ was owed to the oxidation with sulfate of $76 \mathrm{mg} \mathrm{L}^{-1}$ as electron acceptor, and the rest to other metabolic mechanism. Isolation and identification of heterotrophic bacteria revealed a diversified consortium comprising four facultative anaerobic species, Bacillus sp., Paenibacillus sp., Bacteroides sp. and Staphylococcus sp., without sulfate-reducing bacteria detected. Their contribution to AHS biodegradation and sulfate reduction under the special conditions with high oxidization-reduction potential and insufficient electron acceptors has not been known yet. Further work is underway to investigate their properties and respective duties in the consortium.
\end{abstract}

(ㄷ) 2008 Elsevier Ltd. All rights reserved.

\section{Introduction}

Landfill leachate from sanitary landfill site contains a lot of dissolved organic matter (DOM), mainly including volatile fatty acid (VFA) and aquatic humic substance (AHS) such as fulvic acids (FA) with a relatively high carboxyl and aromatic hydroxyl group density, and humic acids (HA) with a significant amount of hydrolysable amino acids (Harmsen, 1983). Contents of the two fractions in leachate vary greatly depending on the landfill age. In young landfills, a majority of organic carbon is present as VFA, as much as $95 \%$ of the organic content (Harmsen, 1983). In mature landfills, however, humic-like compounds dominate the organic fraction in methanogenic leachate, as much as 60\% (Artiola-Fortuny and Fuller, 1982).

Biological processes are effective for the removal of VFA, but less so for FA and HA, and only physicochemical methods can remove AHS completely (Albrechtsen, 1994; Renoua et al., 2007). So far, research work concerning biological decomposition of AHS in leachate is fairly scarce, much less complete mineralization, and only a few related investigations are available. About $70 \%$ of the humics in the leachate is removed using the biological activated carbon fluidized bed process under aerobic conditions (Imai et al., 1995). Refractory organic matters generally degrade readily

\footnotetext{
* Corresponding author. Tel./fax: +86 1062849133.

E-mail address: liujxrcees@sina.com (J.-X. Liu).
}

under aerobic conditions, but very sparingly under anaerobic conditions. However, substantial degradation of DOM in the anaerobic part of an old leachate plume has been reported (Lyngkilde and Christensen, 1992). Recent observations have suggested a significant potential for anaerobic degradation of aromatic fractions in leachate such as toluene and xylenes, and indicated that the biodegradation is related to methanogenesis, sulfate reduction and iron reduction (Rugge et al., 1995, 1999; Bjerg et al., 1999). These reports could not give direct and detailed information on the microorganisms and changes of structure and component of AHS in a biological process, despite proposing the biodegradation of AHS or organic fractions in AHS.

In our study, the landfill leachate, from a 6 yr old municipal solid waste sanitation landfill site in Beijing of China, is continuously treated to acquire the removal of ammonium $\left(\mathrm{NH}_{4}^{+}\right)$and DOM by a combined process, consisting of a partial nitritation reactor (PNR), an anaerobic ammonium oxidation (Anammox) reactor (AR) and underground soil infiltration systems (USIS) (Liang and Liu, 2008). AR mainly functions as an inorganic nitrogen remover with autotrophic Anammox microorganisms, and however, parts of AHS and dissolved organic carbon (DOC) are removed simultaneously in the reactor. Steady-state removal during a long period (166 d) and total nitrogen analyses have excluded the possibilities of microorganism adsorption and heterotrophic denitrification (Liang and Liu, 2008). In this work, we conducted a number of analyses of these refractory organics using carbon (AHS and DOC) analyses, gel 
permeation chromatogram (GPC), UV/Vis spectroscopy, infrared spectroscopy, and isolation of microorganisms, making it possible to study the conversion and chemical characterization of AHS and to investigate the reasons for the AHS removal from the leachate in the AR.

\section{Materials and methods}

\subsection{Landfill leachate and reactor system}

Detailed characteristics of the raw leachate and operative scheme of AR could be seen in the previous report (Liang and Liu, 2008). During the 166 d continuous running, raw leachate with high-concentrations of $\mathrm{NH}_{4}^{+}-\mathrm{N}\left(1430-2720 \mathrm{mg} \mathrm{L}^{-1}\right)$ and chemical oxygen demand (COD) $\left(1170-2600 \mathrm{mg} \mathrm{L}^{-1}\right)$ was firstly fed to the PNR for the removal of VFA and acquirement of mixture with proper nitrite/ammonium ratio. The effluent from the unit with $\mathrm{NH}_{4}^{+}-\mathrm{N}$ (506-885 $\left.\mathrm{mg} \mathrm{L}^{-1}\right), \mathrm{NO}_{2}^{-}-\mathrm{N}\left(441-1011 \mathrm{mg} \mathrm{L}^{-1}\right)$ and COD (303$954 \mathrm{mg} \mathrm{L}^{-1}$ ) was further purified in the AR. Finally the AR effluent was fed to USIS for advanced treatment. AR, a bench scale fixed biofilm reactor with working volume of $36 \mathrm{~L}$, was strictly airproofed for preventing oxygen introduction from air and coated with silver paper for avoiding illumination. During the entire operational period, temperature in the reactor was maintained at $30 \pm 1{ }^{\circ} \mathrm{C}$, the $\mathrm{pH}$ value was controlled at the range of 7.5-8.0, and the oxidization-reduction potential (ORP) was continuously monitored with an ORP meter (Oxi 330i WTW, Germany).

\subsection{Analytical methods}

A set of water samples from the influent and effluent of AR was simultaneously taken and then filtered with $0.45 \mu \mathrm{m}$ membrane for the following analyses. AHS was evaluated according to APHA (1998) (Method 5510 C) using XAD-7 resin (Rohmhaas Co., USA) (APHA, 1998). A TOC analyzer (Phoenix 8000, Tekmar Dohrmann, USA) was used for measuring the DOC concentration. The molecular weight (MW) distribution was determined by GPC (Millot et al., 1987) using G-50 Sephadex gel (Pharmaracia, Sweden). All GPC fractions were collected with a collector (BSZ-100, Shanghai, China) and then characterized by measuring the TOC. UV/Vis spectrum was recorded on a spectrophotometer (Hewlett-Packard Company, Wilmington, DE) from 190 to $800 \mathrm{~nm}$. For infrared spectroscopic investigations, after being ground and then homogenized with an agate mortar, $0.6 \mathrm{mg}$ air-dried sample was mixed with $200 \mathrm{mg}$ potassium bromide (infrared-grade, Aldrich Chemical Co.) and pressed into a pellet. The pellet was immediately measured from 4000 to $400 \mathrm{~cm}^{-1}$ by using a Fourier transform infrared spectrometer (FTIR-300E, Jasco).

\subsection{Isolation and identification of microorganisms}

Dominant microorganisms capable of utilizing AHS were isolated from biofilm in the AR using the dilute suspension technique and repeated streaking on agar plates. The selective nutrient agar medium, containing AHS extracted from the AR influent as the sole carbon and nitrogen sources, was used to enumerate heterotrophic bacteria. All chemicals and vessels were autoclaved at $120^{\circ} \mathrm{C}$ for $15 \mathrm{~min}$. Plates in triplicate were prepared for each dilution and incubated under $30^{\circ} \mathrm{C}$ and strictly anaerobic conditions like those in the AR for $7 \mathrm{~d}$, and then the colonies were counted. Morphologically dissimilar colonies were selected randomly, numerically dominant culturable colonies were isolated and then purified and finally identified up to genus level according to their morphological, biochemical and physiological characteristics (Holt et al., 1994). Photomicrographs were acquired by a scanning electron
Table 1

Changes of AHS and DOC in the influent and effluent of $\mathrm{AR}^{\mathrm{a}}$.

\begin{tabular}{lllllllll}
\hline $\begin{array}{l}\mathrm{AHS}(\text { Inf.) } \\
\left(\mathrm{mg} \mathrm{L}^{-1}\right)\end{array}$ & $\begin{array}{l}\mathrm{AHS}(\mathrm{Eff} .) \\
\left(\mathrm{mg} \mathrm{L}^{-1}\right)\end{array}$ & $\begin{array}{l}\mathrm{DOC}(\text { Inf.) } \\
\left(\mathrm{mg} \mathrm{L}^{-1}\right)\end{array}$ & $\begin{array}{l}\mathrm{DOC}(\mathrm{Eff}) \\
\left(\mathrm{mg} \mathrm{L}^{-1}\right)\end{array}$ & $\begin{array}{l}R_{1} \\
(\%)\end{array}$ & $\begin{array}{l}R_{2} \\
(\%)\end{array}$ & $\begin{array}{l}P_{1} \\
(\%)\end{array}$ & $\begin{array}{l}P_{2} \\
(\%)\end{array}$ & $\begin{array}{l}P_{3} \\
(\%)\end{array}$ \\
\hline 228 & 288 & 136 & 60 & 53 & 79 & 67 & 90 \\
\hline${ }^{a} R_{1}$ and $R_{2}$ mean the removal efficiencies of AHS and DOC, respectively. $P_{1}, P_{2}$ and \\
$P_{3}$ mean the percentages of AHS(Inf.) to DOC(Inf.), AHS(Eff.) to DOC(Eff.) and the \\
removed AHS to the removed DOC, respectively.
\end{tabular}

microscopy (SEM) (Philips Feiquanta-200) and a transition electron microscopy (TEM) (Hitachi S-600).

\section{Results and discussion}

\subsection{Changes of AHS and DOC}

Biological pretreatment in PNR removed almost all of the biodegradable organics from the raw leachate, resulting in the higher content of AHS in the influent of AR, as presented in Table 1. The further treatment in AR achieved the simultaneous removal of AHS and DOC and the reduction of the percentage of AHS to DOC, suggesting that the removed AHS was certainly mineralized, if not, DOC could not simultaneously removed, and that the removed DOC mainly comprised AHS, as calculated $90 \%$.

\subsection{Changes of MW distribution of DOM}

The fractions of the leachate in terms of MW were separated into three groups, which included (1) $>10 \mathrm{kDa}$, (2) $0.2-10 \mathrm{kDa}$ and (3) $<0.2 \mathrm{kDa}$, representing component A (HA), component B (FA) and component $C$ (other DOM with lower MW), respectively (Fig. 1). According to Table 2, FA was the major fraction in the influent, and AHS (summation of FA and HA) dominated the DOC of the influent, in agreement with the results in Table 1 . As a result of Anammox treatment, the three components were partially removed. Fifty-seven and thirty-three percentage of the removed total DOC were credited to FA and HA, respectively, and only $10 \%$ was related to the component $C$. It was obvious that, therefore, the degradation of FA and HA should bear absolute responsibility for the removal of DOC and AHS, especially that of FA. FA seemed to be more readily degradable than HA in the AR. Effective treatment for AHS decreased the contents of organic fractions with high MW, especially that of FA.

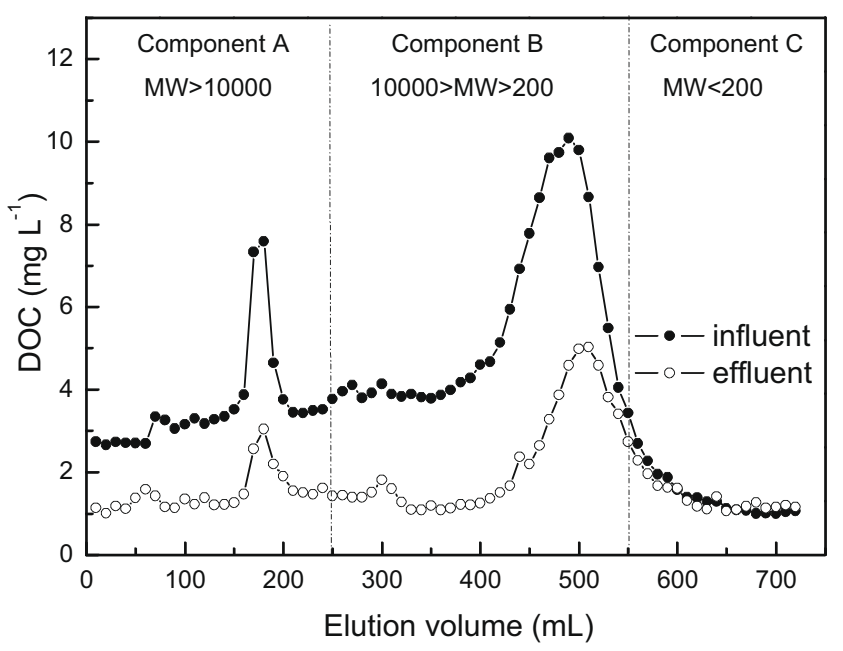

Fig. 1. Molecular weight distribution of DOM in the influent and effluent of AR. 
Table 2

Molecular weight distribution in the influent and effluent of AR.

\begin{tabular}{|c|c|c|c|c|}
\hline \multicolumn{3}{|l|}{ Component } & \multirow{2}{*}{$\begin{array}{c}\text { Influent } \\
87\end{array}$} & \multirow{2}{*}{$\frac{\text { Effluent }}{36}$} \\
\hline Component A & DOC & $\mathrm{mg} \mathrm{L}^{-1}$ & & \\
\hline \multirow[t]{3}{*}{$\mathrm{MW}>10 \mathrm{kDa}$} & $\begin{array}{l}\text { The proportion of A to the } \\
\text { total DOC }\end{array}$ & $\%$ & 31 & 28 \\
\hline & Removal efficiency & $\%$ & & 59 \\
\hline & $\begin{array}{l}\text { The proportion of removed } \mathrm{A} \\
\text { to total removed } \mathrm{DOC}\end{array}$ & $\%$ & & 33 \\
\hline Component B & DOC & $\mathrm{mg} \mathrm{L}^{-1}$ & 132 & 45 \\
\hline \multirow[t]{3}{*}{$0.2<\mathrm{MW}<10 \mathrm{kDa}$} & $\begin{array}{l}\text { The proportion of B to the } \\
\text { total DOC }\end{array}$ & $\%$ & 47 & 35 \\
\hline & Removal efficiency & $\%$ & & 66 \\
\hline & $\begin{array}{l}\text { The proportion of removed B } \\
\text { to the total removed DOC }\end{array}$ & $\%$ & & 57 \\
\hline Component C & DOC & $\mathrm{mg} \mathrm{L}^{-1}$ & & 48 \\
\hline \multirow[t]{5}{*}{$\mathrm{MW}<0.2 \mathrm{kDa}$} & $\begin{array}{l}\text { The proportion of } \mathrm{C} \text { to the } \\
\text { total DOC }\end{array}$ & $\%$ & 63 & 37 \\
\hline & Removal efficiency & $\%$ & 22 & 23 \\
\hline & $\begin{array}{l}\text { The proportion of removed } \mathrm{C} \\
\text { to the total removed } \mathrm{DOC}\end{array}$ & $\%$ & & 10 \\
\hline & The total DOC & $\mathrm{mg} \mathrm{L}^{-1}$ & 282 & 129 \\
\hline & Removal efficiency & $\%$ & & 54 \\
\hline
\end{tabular}

It should be explained about the slight difference between the total DOC value in Table 1 and that in Table 2. The former was from the analysis value of sample, and the latter from the summation of DOC values of three components. Moreover, according to the summation of component $A$ and component B in Table 2, AHS values in the influent and effluent were 219 and $81 \mathrm{mg} \mathrm{L}^{-1}$ with the proportions of AHS to the total DOC of $78 \%$ and $63 \%$, respectively, nearly equal to those in Table 1, suggesting that the data were credible and that the component partition in the MW distribution was feasible.

\subsection{UV/Vis analyses}

The UV/Vis spectra of the influent and effluent exhibited the same decreases in absorbance with wavelength (Fig. 2), and moreover, the decreases were much more rapid than those reported for HS from other origins (Chen et al., 2002), resulting in their absorbances approaching zero at 460 and $360 \mathrm{~nm}$, respectively, suggesting that DOM in them primarily consisted of shorter-wavelength

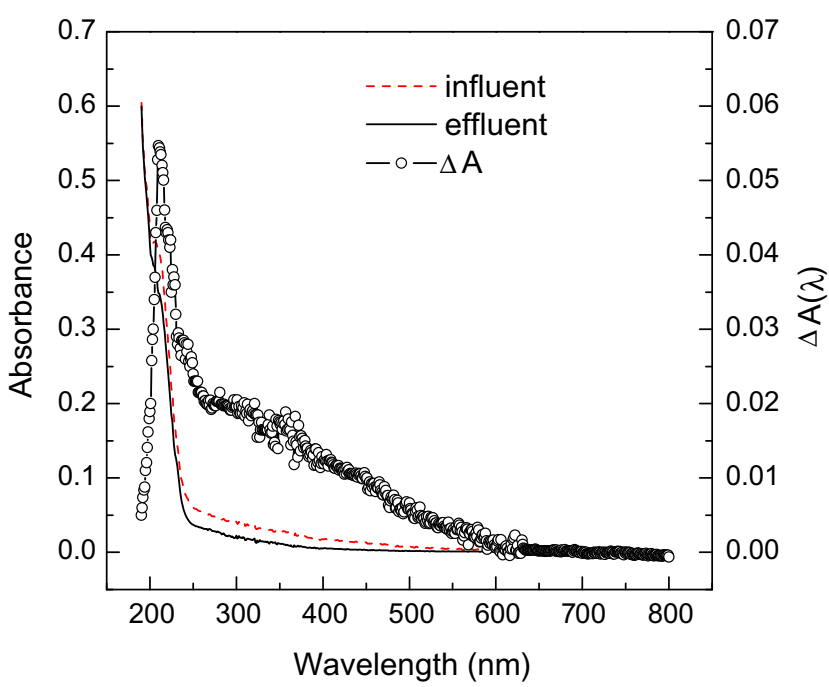

Fig. 2. UV/Vis spectra of influent and effluent of $A R$. $\Delta A$ represents the change in the absorbance of two samples (influent minus effluent).
Table 3

The UV/Vis characteristics and color coefficients of influent and effluent of AR.

\begin{tabular}{llll}
\hline & $E_{2.7 / 4}$ & $E_{4 / 6}$ & Ratio of $E_{4 / 6}$ to $E_{2.7 / 4}$ \\
\hline Influent of AR & 2.9 & 12.4 & 4.2 \\
Effluent of AR & 5.7 & 6.5 & 1.1
\end{tabular}

absorbing chromophores and auxochromes. Differently, the absorption intensity of the effluent obviously fell, leading to the differential absorbance $(\Delta A)$ more than zero for all wavelengths, especially within the two ranges of $200-220 \mathrm{~nm}$ and 240 $400 \mathrm{~nm}$ (Fig. 2). The fact of $\Delta A>0$ for all wavelengths demonstrated that Anammox treatment caused the absorbance of AHS in the effluent to fall. Above two wavelength ranges could be mainly defined as ketonic $\mathrm{C}=\mathrm{O}$ and aromatic $\mathrm{C}=\mathrm{C}$ light absorption bands, respectively (Chen et al., 2002), and absorption of AHS is affected by the relative abundance of these chromophores (Leenheer et al., 1987). Therefore the remarkable absorbance decreases within them should be attributed to the reduced contents of ketonic and aromatic compounds by the Anammox process.

$E_{4 / 6}$ is the ratio of absorbance at $400 \mathrm{~nm}$ to that at $600 \mathrm{~nm}$. Relatively high optical value of $E_{4 / 6}$ further confirmed that the influent largely comprised FA (Table 3) (Christensen et al., 1998; Chen et al., 2002). On the other hand, it was reduced to 6.5 in the effluent, proving that absorption intensity in ultraviolet range was remarkably weakened due to Anammox treatment. $E_{2.7 / 4}$ is the ratio of absorbance at $270 \mathrm{~nm}$ to that at $400 \mathrm{~nm}$. Color coefficients in the effluent also had significant changes, including the decrease in the ratio of $E_{4 / 6}$ to $E_{27 / 4}$, suggesting the decreases in the degree of polymerization and aromaticity, and the increase in $E_{2.7 / 4}$, meaning a more degradation of long-wavelength absorbing chromophores such as quinoid and carboxylic aromatic compounds than that of short-wavelength absorbing chromophores such as ketones (Lipski et al., 1999).

UV/Vis spectrum analyses yielded well comparable results with those in carbon analyses and MW distribution. The higher absorption intensity of influent depended on the higher condensation degree of the aromatic rings and the large MW, and correspondingly, decreasing absorbance in the effluent resulted from the removal of AHS with higher MW and degradation of aromatic and ketonic chromophores.

\subsection{FTIR analyses}

As compared with influent, the FTIR spectrum of effluent displayed substantial changes as follows (Fig. 3): (1) new absorption peaks appeared in the two regions of $2920-2850 \mathrm{~cm}^{-1}$ and $1170-1000 \mathrm{~cm}^{-1}$; (2) some absorption peaks disappeared in the bands at 3570-3419, 1680, 850 and $617 \mathrm{~cm}^{-1}$.

The weak shoulders at 2850 and $2920 \mathrm{~cm}^{-1}$ indicated the appearance of organic matter containing aliphatic methylene (Stevenson, 1982). The three emerging bands in the region from 1000 to $1170 \mathrm{~cm}^{-1}$, suggested the presence of carbohydrates and polysaccharide-like substances in the effluent (Stevenson, 1982). The disappearing bands at 3570-3419, 1680 and $850 \mathrm{~cm}^{-1}$ implied the complete removal or transformation of organic components containing phenolic $\mathrm{O}-\mathrm{H}$ or $\mathrm{N}-\mathrm{H}$ stretch, $\mathrm{C}-\mathrm{O}$ vibration of aldehyde and $\mathrm{N}-\mathrm{H}$ stretch of primary amine, respectively (Gigliotti et al., 1999; Smidt and Meissl, 2007). Increasing absorbance at $1271 \mathrm{~cm}^{-1}$ often indicates the release of organic mono-molecules from cracked macromolecules and their subsequent degradation (Stevenson, 1982; Smidt and Meissl, 2007). In this study, the obviously intensified band at $1271 \mathrm{~cm}^{-1}$ in the effluent spectrum revealed that degradation of refractory HA and FA indeed occurred, leading to the effluent with higher contents of carboxylic and other 


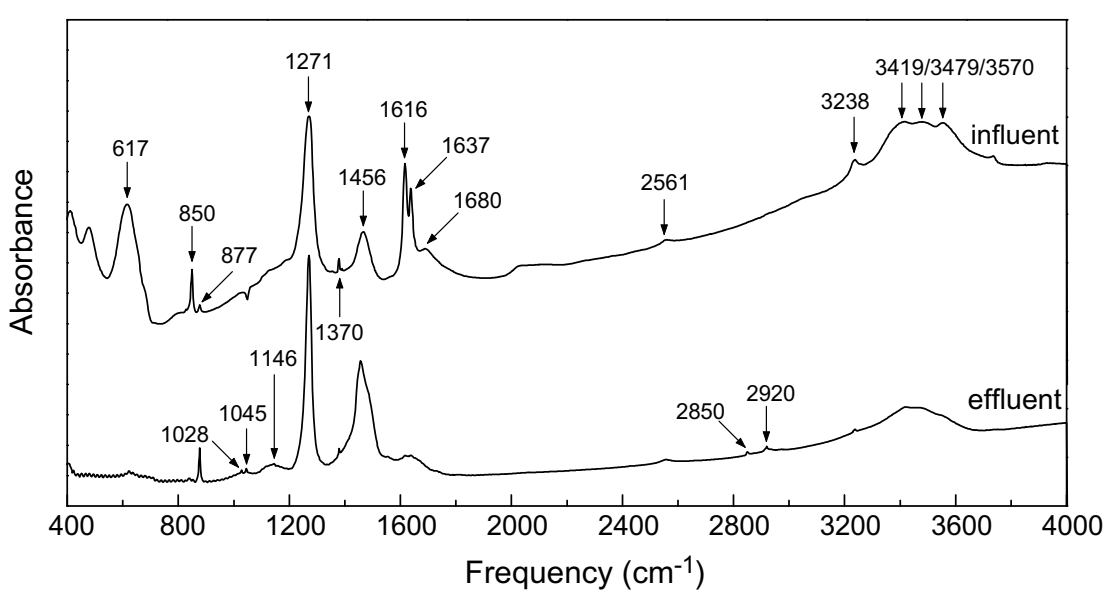

Fig. 3. The FTIR spectra of influent and effluent of AR.

oxygen-containing groups with lower MW. Another improved absorbance at $1456 \mathrm{~cm}^{-1}$ further presented the production of aliphatic organics (Stevenson, 1982; Smidt and Meissl, 2007). Above two intensified bands clearly disclosed the fact of aromatic-ring cleavage, resulting in more aliphatic and carboxylic organics in the effluent. The dark color of HS is primarily caused by quinoidlike structures and ketonic $\mathrm{C}=\mathrm{O}$ in conjugation. Therefore, the strongly weakened absorbances at 1616 and $1637 \mathrm{~cm}^{-1}$ were weighty evidences to confirm that the contents of color-producing groups such as aromatic and ketonic were reduced remarkably in the AR (Stevenson, 1982; Smidt and Meissl, 2007), in consistent with the decolorizing results.

Additionally, the changes of inorganic functional groups such as the reduced absorbances at 1370 and $3238 \mathrm{~cm}^{-1}$ indicated the reduced condensation degrees of nitrite and ammonium in the effluent, respectively (Stevenson, 1982), further proving the occurrence of the autotrophic nitrogen removal (Liang and Liu, 2008). Moreover, the disappearing vibration at $617 \mathrm{~cm}^{-1}$ could reveal the complete reduction of sulfate (Smidt and Meissl, 2007), combined with the detected $\mathrm{H}_{2} \mathrm{~S}$ in the exhaust gas from the AR (data not shown here).

Above all observations could be combined to prove that portions of aromatic organic matters or organics with unsaturated bonds were disintegrated into aliphatic organics and carboxylic acids. However, only the conversion of organic functional group could not cut down the DOC and AHS simultaneously, and so, it was certain that disintegration products were further mineralized into inorganic carbon subsequently, namely, $\mathrm{CO}_{2}$. Produced $\mathrm{CO}_{2}$ might be resolved into water or escape from reactor. AR was a strictly anaerobic reactor, that is, introduction of atmospheric $\mathrm{CO}_{2}$ was not admitted, and thus, the detected $\mathrm{CO}_{2}$ from exhaust gas undoubtedly proved the formation of $\mathrm{CO}_{2}$ in the $\mathrm{AR}$ (average level of $\mathrm{CO}_{2}$ in the AR was detected to be about 18000 ppm). Additionally, strong increase in absorbance at $877 \mathrm{~cm}^{-1}$ representing $\mathrm{C}-\mathrm{O}$ of inorganic biocarbonate (Smidt and Meissl, 2007) obviously indicated that, some of yielded $\mathrm{CO}_{2}$ was resolved into water, leading to the increasing concentration of biocarbonate in the effluent. Autotrophic nitrogen removal in the AR was carbonate demanding, it was concluded that, therefore, carbonate-consuming rate in the Anammox process should be less than carbonate-forming rate in the mineralization of AHS.

By providing more detailed information about the changes of DOM functional groups and inorganic components between influent and effluent, FTIR spectra further testified that, Anammox process did not only remove the inorganic nitrogen effectively, but decomposed and mineralized part of aromatic and ketonic components, which was the main reason for the decreases in MW and UV absorbance in the effluent, ultimately leading to the simultaneous removal of AHS and DOC from influent.

\subsection{Isolation and identification of heterotrophic microorganisms in the AR}

Four facultative anaerobic strains, capable of utilizing AHS as the sole carbon source and propagating in the culture plate, were isolated and classified into Bacillus sp., Paenibacillus sp., Bacteroides sp. and Staphylococcus sp., respectively (Fig. 4). In the consortium, Bacillus dominated $45 \%$, followed by Paenibacillus with $25 \%$, and Staphylococcus was in a relative low content with $13 \%$. These species have not been reported so far to our knowledge for the degradation of AHS from landfill leachate under anaerobic conditions, nevertheless they have exhibited good abilities in decomposing and mineralizing refractory organics from other origins in a mixed form, such as polychlorophenol, lignocellulose and petroleum hydrocarbons (Mannisto et al., 2001; Suarez-Estrella Vargas-Garcia et al., 2007; Ferguson et al., 2008), meaning that they have potential as degraders of refractory organics, especially that of aromatic polymer.

In this work, biological sulfate reduction and organics oxidation certainly occurred as evidenced by the disappearance of sulfate, produced hydrogen sulfide, removed DOC, increasing biocarbonate and produced $\mathrm{CO}_{2}$. The most extensively known microorganisms concerning bio-reduction for sulfate are the sulfate-reducing bacteria (SRB). However, there were no SRB detected in the AR. Recent studies have noticed the absence of SRB in the microbial communities responsible for sulfate reduction (Rajasekar et al., 2005). In this study, it should be impossible for SRB to live in the habitats with high ORP (generally more than $+100 \mathrm{mV}$ ), caused by the high strength nitrite in the influent (Liang and Liu, 2008). Therefore, it might be other heterotrophic organisms to reduce sulfate with suitable organic compounds as electron donors in the same way as SRB. The four isolates mentioned above have been known to be capable of achieving catabolism via both fermentation and anaerobic respiration with oxygen-containing inorganic compounds as electron acceptors, for example, nitrate. So far, few reports have related the anaerobic metabolism with sulfate for bacteria except for SRB. For all that, it could be presumed that the four isolates might have the ability to carry out a diversity of anaerobic respiration and to use a variety of electron acceptors, and thus might be stimulated by a suitable organics for sulfate reduction, just like Bacillus and Staphylococcus strains involved in microbiological selenium reduction (Siddique et al., 2006). However, whether the suitable organic matter is AHS itself or its intermediates needs further investigation. 

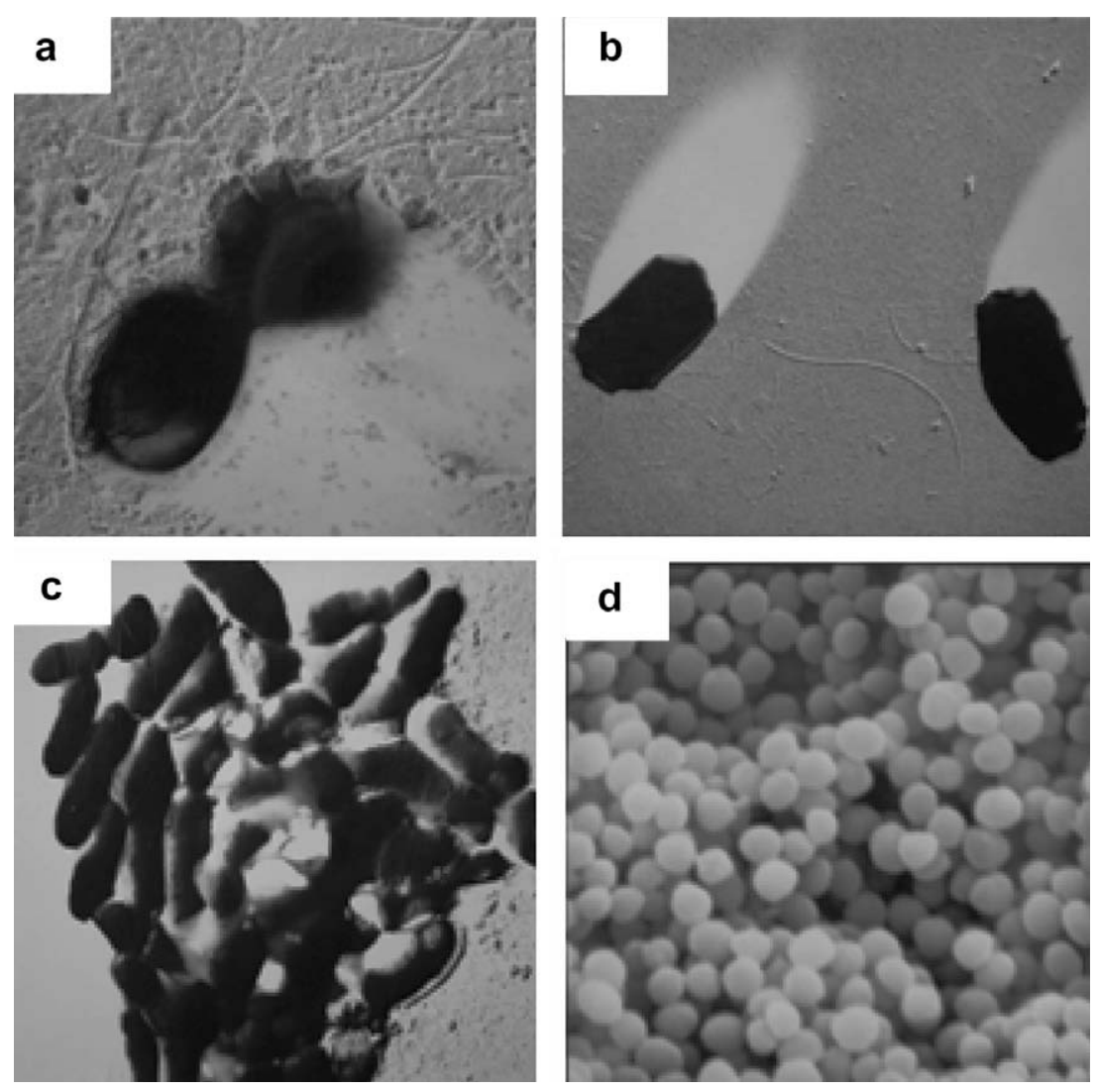

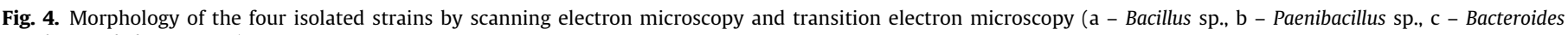
sp., d - Staphylococcus sp.).

It has been demonstrated that AHS can be serve as electron donors to be oxidized for Fe(III)-reducing microorganisms growing on electron acceptors, such as nitrate and fumarate (Lovley et al., 1999), indicating that AHS may play an important role as an electron donor in anaerobic environments. However, few studies have reported the role of sulfate as suitable electron acceptor to oxidize AHS in landfill leachate yet (Liamleam and Annachhatre, 2007). Results in this work certainly indicated the correlation between anaerobic oxidization of AHS and sulfate reduction, which should be established by the metabolic activities of the four strains.

It was reported here for the first time that the bacteria detected showed potential as degrader of AHS in the landfill leachate in such habitats without molecular oxygen and with high ORP. However, at this stage, their precise roles in AHS biodegradation and sulfate reduction have not been known yet. Further studies are underway in order to categorically evaluate their properties in this work, separately and in consortia.

\subsection{Possible pathway of AHS mineralization}

Simultaneous removal of AHS and DOC, along with increasing biocarbonate and produced $\mathrm{CO}_{2}$ adequately proved the mineralization of AHS in the AR, on the other hand, decreases in contents of aromatic groups, combined with increases in contents of carboxylic and aliphatic groups, further indicated that the mineralization was completed by way of cleavage of aromatic-ring and oxidation of low-MW intermediates.

Under absolute absence of molecular oxygen conditions, phosphates, nitrates and sulfates can become the principal oxidants and terminal acceptors of the electrons generated in the biodegradation of organic matter (Claypool and Kaplan, 1974). Very low concentrations of nitrate and phosphate in the leachate excluded their possibilities as electron acceptors to oxidize AHS (data not shown here). Despite high-concentration nitrite in the AR, previous study has confirmed that the nitrite removal was not owed to denitrification but dominantly to the autotrophic Anammox process (Liang and Liu, 2008), and moreover, there were no heterotrophic denitrifiers detected. Thus biological oxidation of AHS via nitrite was also impossible.

Landfill leachate usually contains a certain concentration of sulfate and anaerobic treatment of biodegradable organics in leachate by microbiological sulfate reduction has been researched (Henry and Prasad, 2000). In this study, despite the failure in the SRB isolation, the fact of sulfate reduction positively favored the deduction that sulfates functioned as electron receiver in the anaerobic respiration. Generally, low-MW and readily biodegradable organic compounds are suitable electron donors for sulfate reduction (Liamleam and Annachhatre, 2007), however, enriched bacterial cultures have been found to degrade and mineralize saturated aromatic or unsaturated non-aromatic hydrocarbons via sulfate reduction (Kniemeyer et al., 2003). In this study, there might be two kinds of sulfate reduction mechanisms in terms of different electron donors: (1) phenolic or other aromatic fraction in AHS was directly attacked as reducer, and (2) small size intermediates acted as terminal electron donors.

Theoretically, biological reduction of sulfate of $76 \mathrm{mg} \mathrm{L}^{-1}$ in the influent could cause the complete oxidation of $51 \mathrm{mg} \mathrm{L}^{-1}$ organics. However, nearly $137 \mathrm{mg} \mathrm{L}^{-1}$ AHS was removed (Table 1 ), meaning that other electron acceptors than sulfate might be involved in the oxidation of the rest $86 \mathrm{mg} \mathrm{L}^{-1}$ AHS via other pathway than sulfate reduction. However, only sulfate might serve as electron receiver in this study, and averagely $0.95 \mathrm{mg} \mathrm{L}^{-1} \mathrm{Fe}(\mathrm{II})$ in the influent could not play a role here (Liang and Liu, 2008). Thus it was inferred that containing-oxygen functional groups such as $\mathrm{C}=\mathrm{O}$ of quinoid and 
ketones, $\mathrm{C}-\mathrm{O}$ of carboxylic acids and phenolic $\mathrm{O}-\mathrm{H}$, might play a role here. More studies are needed to evaluate this hypothesis.

\section{Conclusions}

The present research using Anammox process for treating landfill leachate showed stable and significant removal for AHS, and the results reported in this work evidently indicated that the removed AHS was decomposed and mineralized. Microbiological sulfate reduction was one of reasons, and other metabolic pathway should bear the main responsibility. Although there were no SRB species detected, the possibility of the existence of them due to lack of nitrites in the inner part of the biofilm, should be further investigated. Four facultative anaerobic species, Bacillus sp., Paenibacillus sp., Bacteroides sp. and Staphylococcus sp., showed their potential as degraders of AHS in the landfill leachate. But their contribution to the complete biodegradation of AHS and the reduction of sulfate in the AR where ORP was high and there were not enough electron acceptors for the complete oxidation of AHS, has not known yet, and need categorical confirmation in the further work.

\section{Acknowledgements}

The authors are grateful to the financial support from the National Natural Science Foundation of China (No. 50538090) and the National Hi-Tech Development Plan (863 Plan) in China (No. 2002AA649250).

\section{References}

Albrechtsen, H.J., 1994. Distribution of bacteria, estimated by a viable count method, and heterotrophic activity in different size fractions of aquifer sediment. Geomicrobiol. J. 12, 253-264.

APHA, 1998. Standard Methods for the Examination of Water and Wastewater, 20th ed. American Publish Health Association, Washington, DC.

Artiola-Fortuny, J., Fuller, W.H., 1982. Humic substances in landfill leachates: I. Humic acid extraction and identification. J. Environ. Qual. 11, 663-668.

Bjerg, P.L., Rugge, K., Cortsen, J., Nielsen, P.H., Christensen, T.H., 1999. Degradation of aromatic and chlorinated aliphatic hydrocarbons in the anaerobic part of the Grindsted landfill leachate plume: In situ microcosm and laboratory batch experiments. Ground Water 37, 113-121.

Chen, J., Gu, B., LeBoeuf, E.J., Pan, H., Dai, S., 2002. Spectroscopic characterization of the structural and functional properties of natural organic matter fractions. Chemosphere 48, 59-68.

Claypool, G.E., Kaplan, I.R., 1974. The origin and distribution of methane in marine sediments. In: Kaplan, I.R. (Ed.), Natural Gases in Marine Sediments. Plenum Press, New York, pp. 99-139.

Christensen, J.B., Jensen, D.L., Gron, C., Filip, Z., Christensen, T.H., 1998. Characterization of the dissolved organic carbon in landfill leachate-polluted groundwater. Water Res. 32, 125-135.

Ferguson, S.H., Powell, S.M., Snape, I., Gibson, J.A.E., Franzmann, P.D., 2008. Effect of temperature on the microbial ecology of a hydrocarbon-contaminated Antarctic soil: implications for high temperature remediation. Cold Reg. Sci. Technol. 53, 115-129.

Gigliotti, G., Businelli, D., Giusquiani, P.L., 1999. Composition changes of soil humus after massive application of urban waste compost: a comparison between FT-IR spectroscopy and humification parameters. Nutr. Cycl. Agroecosys. 55, 23-28.

Harmsen, J., 1983. Identification of organic compounds in leachate from a waste tip. Water Res. 17, 699-705.

Henry, J.G., Prasad, D., 2000. Anaerobic treatment of landfill leachate by sulfate reduction. Water Sci. Technol. 41 (3), 239-246.

Holt, J.G., Kreig, N.R., Sneath, P.H.A., Stanely, J.T., 1994. In: Williams, S.T. (Ed.) Bergey's Manual of Determinative Bacteriology. Williams and Wilkins Publishers, Maryland.

Imai, A., Onuma, K., Inamori, Y., Sudo, R., 1995. Biodegradation and adsorption in refractory leachate treatment by the biological activated carbon fluidized bed process. Water Res. 29, 687-694.

Kniemeyer, O., Fischer, T., Wilkes, H., Glockner, F., Widdel, F., 2003. Anaerobic degradation of ethylbenzene by a new type of marine sulfate reducing bacterium. Appl. Environ. Microbiol. 69, 760-768.

Leenheer, J.A., Wilson, M.A., Malcolm, R.L., 1987. Presence and potential significance of aromatic-ketone groups in aquatic humic substances. Org. Geochem. 11, $273-280$.

Liamleam, W., Annachhatre, A.P., 2007. Electron donors for biological sulfate reduction. Biotechnol. Adv. 25, 452-463.

Liang, Z., Liu, J.X., 2008. Landfill leachate treatment with a novel process: anaerobic ammonium oxidation (Anammox) combined with soil infiltration system. J Hazard. Mater. 151, 202-212.

Lipski, M., Slawinski, J., Zych, D., 1999. Changes in the luminescent properties of humic acids induced by UV radiation. J. Fluoresc. 9, 133-138.

Lovley, D.R., Fraga, J.L., Coates, J.D., Blunt-Harris, E.L., 1999. Humics as an electron donor for anaerobic respiration. Environ. Microbiol. 1, 89-98.

Lyngkilde, J., Christensen, T.H., 1992. Fate of organic contaminants in the redox zones of a landfill leachate pollution plume (Vejen, Denmark). J. Contam. Hydrol. 10, 291-307.

Mannisto, M.K., Salkinoja-Salonen, M.S., Puhakka, J.A., 2001. In situ polychlorophenol bioremediation potential of the indigenous bacterial community of boreal groundwater. Water Res. 35, 2496-2504.

Millot, N., Granet, C., Wicker, A., Faup, G.M., Navarro, A., 1987. Application of GPC processing system to landfill leachates. Water Res. 21, 709-715.

Rajasekar, A., Maruthamuthu, S., Muthukumar, N., Mohanan, S., Subramanian, P. Palaniswamy, N., 2005. Bacterial degradation of naphtha and its influence on corrosion. Corros. Sci. 47, 257-271.

Renoua, S., Givaudan, J.G., Poulain, S., Dirassouyan, F., Moulin, P., 2007. Landfill leachate treatment: review and opportunity. J. Hazard. Mater. 150, 468-493.

Rugge, K., Bjerg, P.L., Christensen, T.H., 1995. Distribution of organic compounds from municipal solid waste in the groundwater downgradient of a landfill (Grindsted, Denmark). Environ. Sci. Technol. 29, 1395-1400.

Rugge, K., Bjerg, P.L., Pedersen, J.K., Mosbaek, H., Christensen, T.H., 1999. An anaerobic field injection experiment in a landfill leachate plume Grindsted, Denmark. I. Experimental setup, tracer movement, and fate of aromatic and chlorinated compounds. Water Res. 35, 1231-1246.

Siddique, T., Zhang, Y.Q., Okeke, B.C., Frankenberger Jr., W.T., 2006. Characterization of sediment bacteria involved in selenium reduction. Bioresour. Technol. 97, 1041-1049.

Smidt, E., Meissl, K., 2007. The applicability of Fourier transform infrared (FT-IR) spectroscopy in waste management. Waste Manage. 27, 268-276.

Stevenson, F.J., 1982. Humus Chemistry: Genesis, Composition, Reactions, first ed John Wiley, New York.

Suarez-Estrella Vargas-Garcia, F., Lopez, M.J., Moreno, J., 2007. In vitro studies on lignocellulose degradation by microbial strains isolated from composting processes. Int. Biodeter. Biodegr. 59, 322-328 